\title{
Bargaining in Patent Licensing Negotiations under Stochastic Environments: An Experimental Study
}

\author{
Yi-Nung Yang ${ }^{1}$ and Yu-Jing Chiu ${ }^{2}$ \\ ${ }^{1}$ Department of International Business, Chung Yuan Christian University, Chung Li 32023, Taiwan \\ ${ }^{2}$ Department of Business Administration, Chung Yuan Christian University, Chung Li 32023, Taiwan \\ Correspondence should be addressed to Yu-Jing Chiu; yujing@cycu.edu.tw
}

Received 5 July 2013; Revised 16 October 2013; Accepted 23 October 2013; Published 4 March 2014

Academic Editor: Jung-Fa Tsai

Copyright (c) 2014 Y.-N. Yang and Y.-J. Chiu. This is an open access article distributed under the Creative Commons Attribution License, which permits unrestricted use, distribution, and reproduction in any medium, provided the original work is properly cited.

Experiments of a bargaining game between licensors and licensees were conducted. The main treatment is to introduce a "secondchance" negotiation for licensors in a context of ultimatum game. The experimental results reveal that the introduction of the "second-chance" negotiation for licensors has significant impacts on behaviors of the licensors and licensees. This "second-chance" negotiation for licensors essentially increases the average offers made by the licensees, expected willingness-to-accept of the licensors, and offers accepted by the licensors. The market efficiency of patent transaction is improved since the rates of acceptance are strikingly raised. The licensors would be the main beneficiary with this additional opportunity.

\section{Introduction}

Modern economy heavily relies on private innovations of new products, services, or manufacturing process. Rewards as a social incentive for those who have contributed their innovations to development of economies are nowadays legally granted in many forms of intellectual property (hereafter, IP) rights, such as patents, copyrights, and trademarks. In particular, management of these IPRs has become one of the most important strategies and financial assets for many of the current business operations. In this paper, we mainly focus on the patents as a representative of the IPRs.

A patent is the right granted by the officials of a country to the patent holder who is officially authorized to exclude others from commercial use of the invention developed by the patent holder within that country. However, any firm as the patent holder is not naturally awarded monetary payoffs derived from the patent they own. This is because all property rights virtually have some uncertain elements [1]. In general, two kinds of uncertainty are often fundamental for patents. One is uncertainty about commercial importance and the other is uncertainty about enforcement in litigation [2]. These benefits or damages associated with patents would only be awarded with some probability. That is, patents have essentially probabilistic nature as modeled in the literature (e.g., $[3,4])$.

In addition to internal commercialization of their own patents, one of the other common forms for patent holders to generate revenues from the developed patents is to license the patent to third parties [5-7].

A license is a way to transfer certain rights from the licensor to the licensee for a certain time period. A successful licensing transaction can occur not only if both the licensor and the licensee have common knowledge in expect future economic benefits from the transfer of such rights but also if they agree how to split the expected benefits either in terms of a lump sum fixed payment, per-use based, time-based, royalty based, or subscription based methods.

There is a large body of literature studying the issues of valuation of IPRs or strategies of licensing patents (just to name a few, [8-12]). The review of this stream of the literature is beyond the scope of this paper. We restrict our attention to study a narrower issue of bargaining in patent licensing negotiations with the application of experimental approach, which got relatively little attracted in the literature. Over the recent decades, the experimental method arises as one of the important new contribution to behavioral psychology and economics. The experimental approach has successfully 
challenged many fundamental social-scientific assumptions about human rationality and efficiencies in functioning of markets [13]. The growing experimental literature has continued to contribute to knowledge of human society by modifying existing theoretical works and complementing the conventional empirical studies especially on the issues of human behaviors.

In the practice of patent licensing, a licensor would often contact some potential buyers one by one for seeking a better offer of their licenses. Those unsuccessful negotiations were undocumented and then unobservable (this was confirmed by an interview with a manager of the Entrepreneurship and Technology Licensing Center at Chung Yuan Christian University, Taiwan). Only final successful negotiations would be recorded but usually unavailable due to trade secrets. The experimental study is a proper approach to investigate the issue under this situation.

As inspired by the work of Buccafusco and Sprigman [13], the purpose of this paper is to access the effects of "second-chance" negotiation for licensors on licensee's offers and licensor's responses in bargaining games of royalty-based of patent license. For this purpose, we designed a betweensubject treatment which differs in distribution but with the same expected market sales of goods produced with the patent licensed.

The rest of this paper is organized as follows. Section 2 gives a brief review of bargaining games related to patent licensing and describes the design and procedure of the experiments conducted in this paper. Section 3 shows our experimental results. We deliver the summary of our experimental findings and discussions of policy implications from this experiment in the last section.

\section{Design of the Patent Licensing Game}

Application of experimental approach to investigate related issues of licensing patents is paid little attention but is not brand new in the literature. For example, Buccafusco and Sprigman [13] reported an interesting novel application of an experimental method to examine whether transactions in intellectual property are subject to the valuation anomalies commonly referred to as "endowment effects." As pointed by $[11,13]$, for example, the famous ultimatum game as a bargaining process has natural characteristics close to bargaining in patent licensing negotiations. Besides, the ultimatum game has been intensively studied in game theory and experimental economics and/or psychology; it might be one of the next candidate approaches to further examine the often unobserved behaviors in bargaining process over patent licensing.

In a typical ultimatum game, there is a proposer and a responder bargain for dividing a fixed-size stake, $c$. The rule in this game is that the proposer offers a share, $s \in[0, c]$ to the responder. The responder then can accept or reject $s$. If the responder accept $s$, she receives $s$ and the proposer receives the rest of the stake, $c-s$. If the offer is rejected, both the responder and the proposer receive nothing.

One of the theoretical predicted outcomes by standard game theory for this bargaining game is that the responder accepts any nontrivial positive $s$ since she is better off in acceptance of this offer. The other popular approach, the Nash bargaining solution, nevertheless predicts a 50-50 split between proposer and responder in such bargaining games. However, these theoretical predictions seem not to well explain the most of experiment results.

A typical experimental finding of ultimatum games suggests that responders in standard two-player settings often reject small offers and the probability to reject inclines to decrease with $s$. The offers above $50 \%$ of the stake are rare and there are almost no offers below 20\%. While a 50-50 split is often the modal offers, but typical offers accepted are about 30-40 percent of the total $[14,15]$. These observations in the ultimatum game are quite robust for variations in stake sizes, across countries, asymmetric information, subject pools, genders, and many other important factors. A detailed review of this literature can be found in [14, 16-18].

For instance, Hoffman et al. [19] demonstrated a striking experimental result that their \$10- and \$100-stake ultimatum games turned out to be insignificantly different. Roth et al. [20] conducted experiments of ultimatum games in Jerusalem, Ljubljana (in Slovenia), Pittsburgh, and Tokyo. The results are similar to typical ones that proposers generally gave modal offers ranging from $40 \%$ to $50 \%$.

Knez and Camerer [21] found that an increase in stakes does not seem to affect offers and acceptances. Proposers usually make lower offers and responders accept lower offers when stake sizes are unknown to responders [21, 22].

We choose to apply the standard two-person ultimatum game to study the bargaining process in patent licensing negotiations for several reasons. First, the ultimatum game has a nature mimicking bargaining for patent licensing. Second, maybe due to trading secrets, the processes of bargaining licenses for patents are in general unavailable or difficult to obtain for analysis. Experimental methods can complement the existing theoretical and empirical works to get further understanding of problems in licensing patents. It can also allow us to evaluate some novel institutional changes on transactions of patent licenses in advance in the lab, rather than directly implementing immature policies experimentally on cases of the real world which could lead to unpredictable consequences.

The design of our experiments shares some similarities in spirits with [20, 21]. Knez and Camerer [21] extended the ultimatum game to a three-person setting with asymmetric outside options. In their experiment, a single proposer simultaneously makes offers to two responders. If the offers were rejected, the proposer and responders both obtain known amounts of payoffs. They found that the presence of outside options had a striking effect on increasing rejection rate to nearly $50 \%$.

Another ultimatum game performed by Roth et al. [20] was aimed to study this competition effect on ultimatum games. They implemented a market game that there are one responder and nine proposers in their ten-period bargaining game conducted in four different countries in addition to the standard two-person ultimatum games as the benchmarks. In that game, nine proposers simultaneously offer a bid, $b_{i}$, to a responder in dividing a 1000 tokens stake. The responder decides to accept or reject the maximum bid $\left(b_{\mathrm{Max}}\right)$ of nine 
offers. If the responder rejects it, all players receive zero. If the responder accepts it, her payoff is $b_{\text {Max }}$ and the corresponding proposer's payoff is $1000-b_{\text {Max }}$ while the other eight proposers get zero payoffs. Their experimental results show that the bargaining offers converge to the predicted subgame perfect equilibrium in which some proposers make offers close to one and the responder collects almost all gains from trade.

The main design of the experiments in this study differs from Roth et al. [20]. Our ultimatum experiments with two proposers are also trying to introduce competition in bidding the licensing. But in our experiments, the responder decides to accept one of the two offers in turn not decide on the maximum of the two offers at once. The different protocol used in our bargaining experiments may result in different implications. The maximum-offer design in Roth et al. [20] introduced intensifying competition among proposers since that maximum offer will dominate all the others once accepted.

2.1. The Experimental Design. The basic scenario of the bargaining game involves two roles of players, a licensor and a licensee. The licensor who owns a patent wants to license it to a potential licensee in terms of license fee per-unit sold. The licensee once authorized is assumed to produce a good for selling with use of the patent. As pointed out by $[3,4]$, patents have essentially probabilistic nature. In order to capture this nature, we attribute the uncertainty associated with the underlying patent engaged in bargaining to a condition of unknown future sales, which is not known before settlement of the bargaining, of the produced goods with the licensed patent.

The main reason is that the market size is one of the determinants to affect the licensing strategy for firms to market their research results [23]. In a similar design developed by [22], we associate the market uncertainty with different variances of the market size but with the same expected mean sales in order to focus on the impact of variability in these unknown future sales on the bargaining outcome of a licensing game. To be more specific, the high-risk market differs from the low-risk market only in variance of quantities sold in the scenarios of our experiments.

Without loss of generality, the market uncertainty is simplified to assume a fixed price, $p=10$, of the final product but unknown quantities, denoted by $Q_{m, i}$, of future sales which follow a simple random distribution with 50-50 probability to be realized for $i=1$ and 2 for each different market risk state, $m$. That is, we designate two states for our experiments with a between-subject treatment, in which they are termed the low-risk market treatment and high-risk market treatment. To be specific, $Q_{m, i}$ is equal to 100 or 300 million units under the low-risk market treatment conducted in Session 1. $Q_{m, i}$ is equal to 0 or 400 million units under the high-risk market treatment conducted in Session 2. Those quantities are unknown by the licensor and licensee; only the information about the states and the distribution of quantities are publically common knowledge to them before starting the bargaining in the experiments. Note that the mean expected sales are the same but different in variances under the lowand high-market treatments.
The role played in the experiments is randomly decided. After the role being assigned, the licensee first has to write down the expected quantities sold in the future and the licensor has to write down her willingness-to-accept (hereafter, WTA) offer expected on a record sheet, individually and privately. They then engage the bargaining of licensing fee. The licensee proposes an offer $s \in[0,10]$.

Once the bargaining on the per-unit of licensing fee is agreed by both parties, the ex post randomly determined quantities are announced and assumed to be sold for sure by assumptions and payoffs for each role are then calculated and shown. That is, the bargaining decision can be simply relied on negotiating the licensing fees, rather than on other considerations such as inventories or salvages.

After the per-unit of licensing fee, $s$, is agreed, the market outcome is randomly determined according to preannounced distributions in different sessions as stated earlier in this section. The payoffs for licensor is calculated by

$$
\prod_{\text {licensor }}=s \times Q_{m, i},
$$

while payoffs for the licensee is calculated by

$$
\prod_{\text {licensee }}=(10-s) \times Q_{m, i} .
$$

But if no agreement is accepted by both parties, the licensor and licensee both get zero payoffs.

Another important feature in our experimental design is to introduce a "second-chance" negotiation for licensors. This is because the conventional one-shot negotiation in ultimatum game might not be suitable for study bargaining behavior of patent licensing. It is believed that in practice, a patent holder should not restrict herself to negotiate with only one potential licensee. We implement this "second-chance" negotiation for licensors in the experiments by providing a two-licensees treatment in addition to one-licensee treatment as in conventional ultimatum games. We adopted a withinsubject design for the "second-chance" negotiation. In words, subjects in each low- and high-risk market treatments will all first experience the one-licensee experiment in the first tenround rounds (Phase 1) and then perform the two-licensee treatment design in the next ten rounds (Phase 2).

\section{Experimental Procedures and Results}

3.1. The Experimental Procedures. The experiment was conducted at Chung Yuan Christian University in Taiwan. Two sessions were run with a total of 75 students who were recruited publically through posters within the campus. There were 42 and 33 participants in Sessions 1 and 2, respectively. The subjects consisted of 35 graduate students and 40 undergraduates in their junior year. There were 14 students majoring in engineering and 61 students majoring in business. Generally, the Economics course at the introductory level with basic concepts of the game theory is required for business students. All of the undergraduate subjects used to take either one of the two courses, the "Strategy and Transfer of Technology" or "Technology Law and Intellectual Property 
Rights" while the graduate students used to take the course “Technology Management". In those three courses, they were taught the concept of patent licensing.

The experiment was performed manually. Each session lasted within 1 hour. The average monetary payoff per subject was \$105 NT dollars (equivalent to about \$3 US dollars and one-hour payment for local students working part-time). Subjects received oral and written instructions complemented with a PowerPoint presentation (the PowerPoint file is in Chinese and the translation into an English version is available upon request from the authors). After the instructions, questions were answered before conducting the experiment.

Note that in our experiments, members of three-subject group were not virtually anonymous since subjects can see around the classroom but they cannot make sure with whom they bargaining.

In Session 1 (low-risk market treatment) and Session 2 (high-risk market treatment), there were 14 and 11 3-persion groups, respectively. Each group had one patent holder as the responder and two licensees as the proposers bargaining for licensing. The role of each subject was randomly assigned at the beginning and remained constant over all rounds of the experiment. In order to minimize the effects of reputation building, groups were randomly assembled in each round.

The experiments followed the steps repeatedly in each round.

\section{Phase 1}

Step 1. A patent holder writes down her minimum per-unit licensing fee to accept. Two licensees write down the expected sales on a record sheet.

Step 2. The patent holder randomly chooses one of the licensing fees, $s_{1}$, offered and decides to accept the offer or not.

Step 3. A coin is flipped to determine the state of market outcomes, $Q_{m, i}, m=$ Low-risk or High-risk. If the patent holder decides to accept the offer $s_{1}$ in Step 2, she receives $s_{1} Q_{m, i}$, while the proposer gets $\left(10-s_{1}\right) Q_{m, i}$ ECU (experimental currency unit). Otherwise, both receive 0 ECU no matter what the market outcome turns out to be. The other proposer whose offer was not selected always receives 0 ECU.

Note that the agreement of the patent license is only effective in one round. The negotiation will be repeated for each round.

Phase 2. The key procedural difference from Phase 1 is that if the patent holder decides to reject the first randomly chosen offer, she has another chance to inspect the second offer proposed by the other proposer and decide to accept it or not. If the patent holder's decision is to accept the first offer, the second offer cannot be seen. If the patent holder decides to reject the first offer and accept the second offer $s_{2}$, she receives $s_{2} Q_{m, i}$, while the second proposer gets $\left(10-s_{2}\right) Q_{m, i}$ ECU in Step 3. In this situation, the first proposer receives 0 ECU. If it turns out that the patent holder rejects both offers, three subjects in that group all receive nothing.
3.2. The Experimental Results. The experimental results of the average offers, willingness-to-accept (WTA), accepted offers, rates of acceptance, and payoffs for licensor and licensees are presented in Table 1.

3.3. Licensee's Offers. At first, it can be obviously found that the second-chance negotiation for licensors has significant impact on the offers made by licensees. The average offers made by licensees in one-licensee and two-licensee groups are 4.70 and 5.29 under the low-risk market treatment (shown in Table 1). The Mann-Whitney $U$ test $(z=3.25$, one-tailed $P$ value $=0.001$ ) as shown in Table 2 reveals that there is a significant increase in these offers.

Under the high-risk market condition, it is similar to what we observe under the low-risk market treatment. The averages of offers made by licensees in one-licensee and twolicensee groups under the high-risk market treatment are 4.64 and 5.19, respectively (shown in Table 1). The corresponding Mann-Whitney $U$ test $(z=3.477$, one-tailed $P$ value $<0.000)$ in Table 2 also shows a significant increase in offers.

Secondly, it can be seen that the average offers (4.64) in the one-licensee group under the high-risk market treatment is slightly less than the average offers (4.70) under the lowrisk market treatment. This observation is also similar for the average offers made in the two-licensee group. The average offers is 5.19 in two-licensee group under the high-risk market treatment, while the average offers is 5.29 under the low-risk market treatment. The Mann-Whitney tests of the betweensubject comparison are -1.021 (two-tailed $P$ value is 0.307 ) and -0.832 (two-tailed $P$ value is 0.406 ), respectively, which both reveal insignificant differences.

3.4. Licensor's Expected Offers and Responses. It is apparently that the licensors' second-chance negotiation also has positive impact on the expected offers that licensors are willing to accept. The average of expected offers to accept in onelicensee group is 6.10 and the average is raised to 6.29 in two-licensee group under the low-risk market treatment. The average of offer expected to accept also increases by about $11 \%$, from 5.36 to 5.93 under the high-risk market treatment. The Mann-Whitney tests of the within-subject comparison shown in Table 2 confirm the differences of significance.

It is interesting to see the willingness-to-accept offer expected by licensors decreases due to higher risk of market sales. This observation is similar across one- and two-licensee groups. The decreases are significantly different suggested by the statistics of Mann-Whiney tests that are -3.780 with onetailed $P$ value $<0.000$ for one-licensee group and -2.721 with one-tailed $P$ value $=0.003$ for one-licensee group as shown in Table 2.

As to the licensor's response to the offers made by licensees, the second-chance negotiation appears to positively affect the averages of accepted offers. Under the low-risk market condition, the average accepted offer is 5.04 in the onelicensee group whereas the average accepted offer goes up to 5.65 in the two-licensee group. Under the high-risk market treatment, the average accepted offer is 5.07 in one-licensee group and is 5.65 in the two-licensee group. The differences are both statistically significant. The Mann-Whitney tests of 
TABLE 1: Experimental results of averages among treatments.

\begin{tabular}{|c|c|c|c|c|}
\hline \multirow{3}{*}{ Variables } & \multicolumn{4}{|c|}{ Treatments } \\
\hline & \multicolumn{2}{|c|}{ Low-risk market } & \multicolumn{2}{|c|}{ High-risk market } \\
\hline & One-licensee & Two-licensee & One-licensee & Two-licensee \\
\hline Numbers of subjects & \multicolumn{2}{|c|}{42} & \multicolumn{2}{|c|}{33} \\
\hline Offer & 4.70 & 5.29 & 4.64 & 5.19 \\
\hline WTA & 6.10 & 6.29 & 5.36 & 5.93 \\
\hline Accepted offer $(1 \mathrm{st} / 2 \mathrm{nd})^{\mathrm{a}}$ & 5.04 & $5.65(5.78 / 5.41)^{\mathrm{a}}$ & 5.07 & $5.65(5.63 / 5.62)^{\mathrm{a}}$ \\
\hline Rate of acceptance $\%(1 \mathrm{st} / 2 \mathrm{nd})^{\mathrm{a}}$ & 66.4 & $92.9(53.6 / 84.6)^{\mathrm{a}}$ & 70.9 & $96.3(61.3 / 90.3)^{\mathrm{a}}$ \\
\hline \multicolumn{5}{|l|}{ Payoff } \\
\hline licensee & 326.571 & 400.179 & 352.727 & 449.455 \\
\hline licensor & 624.538 & 1056.786 & 718.182 & 1173.818 \\
\hline
\end{tabular}

Note: ${ }^{\mathrm{a}}$ The first and second numbers in parentheses denote the first and second offers from Two-licensee game.

TABLE 2: Mann-Whitney tests of differences among treatments.

\begin{tabular}{|c|c|c|c|c|}
\hline \multirow{2}{*}{ Variables } & \multicolumn{2}{|c|}{ Within-subject } & \multicolumn{2}{|c|}{ Between-subject } \\
\hline & $\begin{array}{l}\text { Low-risk market } \\
\text { One- versus two-licensee }\end{array}$ & $\begin{array}{l}\text { High-risk market } \\
\text { One- versus two-licensee }\end{array}$ & $\begin{array}{c}\text { One-licensee } \\
\text { Low- versus high-risk }\end{array}$ & $\begin{array}{c}\text { Two-licensee } \\
\text { Low- versus high-risk }\end{array}$ \\
\hline Offer & $3.250[0.001]^{\mathrm{a}}$ & $3.477[0.000]^{\mathrm{a}}$ & $-1.021[0.307]^{\mathrm{b}}$ & $-0.832[0.406]^{\mathrm{b}}$ \\
\hline WTA & $2.117[0.017]^{\mathrm{a}}$ & $3.477[0.000]^{\mathrm{a}}$ & $-3.780[0.000]^{\mathrm{a}}$ & $-2.721[0.003]^{\mathrm{a}}$ \\
\hline $\begin{array}{l}\text { Accept offer } \\
\text { /1st accepted } \\
\text { /2nd accepted }\end{array}$ & $\begin{array}{c}2.721[0.003]^{\mathrm{a}} \\
/ 2.948[0.003]^{\mathrm{a}} \\
/ 1.285[0.199]^{\mathrm{b}}\end{array}$ & $\begin{array}{l}/ 3.402[0.000]^{\mathrm{a}} \\
/ 3.402[0.000]^{\mathrm{a}} \\
/ 2.419[0.007]^{\mathrm{a}}\end{array}$ & $-0.378[0.705]^{\mathrm{b}}$ & $\begin{array}{c}-0.378[0.705]^{\mathrm{b}} \\
/-1.285[0.199]^{\mathrm{b}} \\
/ 0.680[0.496]^{\mathrm{b}}\end{array}$ \\
\hline $\begin{array}{l}\text { Acceptance rate } \\
\text { /1st accepted } \\
\text { /2nd accepted }\end{array}$ & $\begin{array}{c}3.704[0.000]^{\mathrm{a}} \\
/-1.550[0.121]^{\mathrm{b}} \\
/ 2.797[0.003]^{\mathrm{a}}\end{array}$ & $\begin{array}{c}3.327[0.000]^{\mathrm{a}} \\
/-1.739[0.082]^{\mathrm{b}} \\
/ 2.721[0.003]^{\mathrm{a}}\end{array}$ & $0.454[0.650]^{\mathrm{b}}$ & $\begin{array}{c}1.436[0.151]^{\mathrm{b}} \\
/ 0.076[0.939]^{\mathrm{b}} \\
/ 1.096[0.273]^{\mathrm{b}}\end{array}$ \\
\hline \multicolumn{5}{|l|}{ Payoffs } \\
\hline Licensee & $1.587[0.112]^{\mathrm{b}}$ & $1.172[0.241]^{\mathrm{b}}$ & $0.151[0.880]^{\mathrm{b}}$ & $1.360[0.174]^{\mathrm{b}}$ \\
\hline Licensor & $2.267[0.012]^{\mathrm{a}}$ & $2.230[0.013]^{\mathrm{a}}$ & $0.529[0.597]^{\mathrm{b}}$ & $1.209[0.226]^{\mathrm{b}}$ \\
\hline
\end{tabular}

Note: Numbers in brackets are $P$ values of Manny-Whitnet $U$ test.

${ }^{a}$ denotes one-tailed test; ${ }^{b}$ denotes two-tailed test.

one-licensee against two-licensee group under the low-risk market and high-risk market conditions are 2.721 (one-tailed $P$ value $=0.003)$ and 3.402 (one-tailed $P$ value $<0.000)$.

According to what are shown in Table 1, we can find that this second chance of negotiation raises not only the firstaccepted offers but also the second-accepted offers. The average of accepted offers in the first bargaining is greater than the average in the second bargaining either under the low-risk market or under the high-risk market treatments. The MannWhiney tests all show highly significant differences except the one comparing the offers accepted in the one-licensee group against the second offers accepted in the two-licensee group where the corresponding two-tailed $P$ value is 0.199 .

It is also found that different levels of market risk seem not to affect the average accepted offers based on the MannWhitney tests of between-subject comparisons for the onelicensee group and the two-licensee group including average, first-, and second-accepted offers in Table 2. The corresponding $P$ values are all greater than 0.15 .

3.5. Acceptance Rates and Payoffs. From Table 1, it is surprisingly found that the treatment with additional bargaining chance for licensors has dramatic influences on the rates of acceptance in the patent licensing experimental game. The average rates of acceptance go up from $66.4 \%$ in the onelicensee group to $92.9 \%$ in two-licensee group under the lowrisk market condition. In the high-risk market situation, the rates of acceptance also increase by $25.4 \%$, from $70.9 \%$ to $96.3 \%$. The within-subject comparisons of the one- against two-licensee groups on acceptance rates indicate significant differences the Mann-Whitney test is 3.704 ( $P$ value $<0.000)$ under the low-risk market treatment and 3.327 ( $P$ value $<0.000)$ under the high-risk market treatment.

With further investigation of the data in Table 1, it is intriguing to see that the major increases come from the secondchance bargaining. In the first bargaining, the rates of acceptance under the low-risk market and under the high-risk market conditions slightly drop down to $53.6 \%$ and $61.3 \%$. However, tests on the differences of within-subject treatments shown in Table 2 do not reveal statistical significance (the Mann-Whitney statistics are -1.550 with two-tailed $P$ value $=0.121$ under the low-risk market condition and -1.739 with two-tailed $P$ value $=0.082$ under the high-risk market condition). By contrast, the rates of acceptance in the second bargaining are significantly increased (the Mann-Whitney statistics are 2.797 with one-tailed $P$ value $=0.003$ under the 
low-risk market condition and 2.721 with two-tailed $P$ value $=0.003$ under the high-risk market condition).

Finally, our experimental results show that the licensee's average payoffs are ranging from 326.5 to 449.5 ECU among all treatments. However, they are not statistically different from one another according to the Mann-Whitney tests as it can be seen in the ninth row of Table 2. The licensor's payoffs show a quite different result from the licensee's no matter under the low-risk and high-risk market treatments. The payoffs of licensors in the one-licensee group signify statistical differences from that in the two-licensee group at 5\% level of significance in both treatments with the low and high market risks. It means that an introduction of the secondchance negotiation in the patent licensing game is relatively advantageous to the licensors.

\section{Concluding Remarks}

We conduct exploratory experiments to access the effects of "second-chance" negotiation for licensors on licensee's offer for licensing fee and licensor's acceptance in a bargaining game. A $2 \times 2$ factorial design is used in this experimental study. The main treatment is without/with an introduction of the "second-chance" negotiation for licensors under low and high levels of market risks in terms of uncertain quantities of goods produced with the authorized patent once licensed. The subjects in the experiment bargaining game will first experience a one-licensee treatment as a control group and a two-licensee treatment in which the licensor will have the second bargaining chance with another licensee if the licensor did not agree to accept the licensing fee offered by the first licensee.

The experimental results show that the introduction of the "second-chance" negotiation for licensors has significant impacts on behaviors of the licensors and licensees. The major observations from the experiments are summarized as follows.

First, the "second-chance" negotiation raises the average offer made by the licensees. Second, the "second-chance" negotiation also increases the willingness- to-accept expected by the licensors. Third, the average accepted offers are higher in the two-licensee group than in the one-licensee group and the mean accepted offers are generally larger in the first negotiation than in the second negotiation. Fourth, the acceptance rates strikingly increases by about $25 \%$ because of an additional chance to negotiate. Finally, the "second-chance" negotiation significantly increases the licensor's payoffs.

In summary, the "second-chance" negotiation for licensors essentially increase the average offers made by the licensees, expected willingness-to-accept of the licensors, and offers accepted by the licensors. The most important implication is that this additional opportunity to bargain may improve the market efficiency of patent transaction since the rates of acceptance increase dramatically. The licensors would be the main beneficiary with this additional opportunity.

In this paper, we only paid our attention to one of the prevailing contracting forms in licensing transactions. There exist many different forms of licensing contracts other than the quantity-based royalty licenses as studied in our experimental study. As mentioned by [24], revenue-based royalty licenses, fixed-fee licenses, profit-based royalty licenses, and even hybrid licenses are interesting business models in both academics and practice. We believe that it would be fruitful to extend our experimental method to examine different effects of various contractual forms on licensing transactions for future research.

\section{Conflict of Interests}

The Institute refers to patents, as a generic term, rather than specific vendor/organization arising out of a particular patent. This research is the neutrality study and accord with research ethics, and does not involve a specific policy or commercial interests. Therefore, there is no conflict of interests issues in our study.

\section{References}

[1] M. Rao, "Valuing intellectual property in licensing transactions," The Licensing Journal, 2008.

[2] M. A. Lemley and C. Shapiro, "Probabilistic patents," The Journal of Economic Perspectives, vol. 19, no. 2, pp. 75-98, 2005.

[3] J. Choi, "Alternative damage rules and probabilistic intellectual property rights: unjust enrichment, lost profits, and reasonable royalty remedies," Information Economics and Policy, vol. 21, no. 2, pp. 145-157, 2009.

[4] J. Farrell and C. Shapiro, "How strong are weak patents?" The American Economic Review, pp. 1347-1369, 2008.

[5] H. W. Chesbrough, Open Innovation: the New Imperative for Creating and Profiting from Technology, Harvard Business School Press, New York, NY, USA, 2003.

[6] H. Chesbrough, "Managing open innovation," Research-Technology Management, vol. 47, no. 1, pp. 23-26, 2004.

[7] H. W. Chesbrough and M. M. Appleyard, "Open innovation and strategy," California Management Review, vol. 50, no. 1, pp. 5776, 2007.

[8] M. C. Chang, J. L. Hu, and C. H. Lin, "The optimal licensing strategy of an outside patentee in vertically-related markets," International Journal of Economics and Finance, vol. 5, no. 3, pp. 102-112, 2013.

[9] F. Cuihong, B. H. Jun, and E. G. Wolfstetter, "Licensing process innovations when losers' messages determine royalty rates," Games and Economic Behavior, vol. 82, pp. 388-402, 2013.

[10] M. I. Kamien and Y. Tauman, "Fees versus royalties and the private value of a patent," The Quarterly Journal of Economics, vol. 101, no. 3, pp. 471-491, 1986.

[11] S. Kishimoto and S. Muto, "Fee versus royalty policy in licensing through bargaining: an application of the Nash bargaining solution," Bulletin of Economic Research, vol. 64, no. 2, pp. 293304, 2012.

[12] J. Pénin, "Strategic uses of patents in markets for technology: a story of fabless firms, brokers and trolls," Journal of Economic Behavior \& Organization, vol. 84, no. 2, pp. 633-641, 2011.

[13] C. J. Buccafusco and C. Sprigman, "Valuing intellectual property: an experiment," Cornell Law Review, vol. 96, no. 1, pp. 1-46, 2010.

[14] C. Camerer and R. H. Thaler, "Anomalies: ultimatums, dictators and manners," The Journal of Economic Perspectives, vol. 9, no. 2, pp. 209-219, 1995. 
[15] E. Fehr and K. M. Schmidt, "A theory of fairness, competition, and cooperation," The Quarterly Journal of Economics, vol. 114, no. 3, pp. 817-868, 1999.

[16] W. Güth and R. Tietz, "Ultimatum bargaining behavior: a survey and comparison of experimental results," Journal of Economic Psychology, vol. 11, no. 3, pp. 417-449, 1990.

[17] A. E. Roth and J. H. Kagel, The Handbook of Experimental Economics, vol. 1, Princeton university press, Princeton, NJ, USA, 1995.

[18] R. H. Thaler, "Anomalies: the ultimatum game," The Journal of Economic Perspectives, vol. 2, no. 4, pp. 195-206, 1988.

[19] E. Hoffman, K. A. McCabe, and V. L. Smith, "On expectations and the monetary stakes in ultimatum games," International Journal of Game Theory, vol. 25, no. 3, pp. 289-301, 1996.

[20] A. E. Roth, V. Prasnikar, M. Okuno-Fujiwara, and S. Zamir, "Bargaining and market behavior in Jerusalem, Ljubljana, Pittsburgh, and Tokyo: an experimental study," The American Economic Review, pp. 1068-1095, 1991.

[21] M. J. Knez and C. F. Camerer, "Outside options and social comparison in three-player ultimatum game experiments," Games and Economic Behavior, vol. 10, no. 1, pp. 65-94, 1995.

[22] A. Rapoport and J. A. Sundali, "Ultimatums in two-person bargaining with one-sided uncertainty: offer games," International Journal of Game Theory, vol. 25, no. 4, pp. 475-494, 1996.

[23] M. G. Xue and L. L. Su, "Optimal patent licensing strategy in patent litigation," in Proceedings of the IEEE International Conference Management Science and Engineering (ICMSE '12), pp. 1569-1574, 2012.

[24] L. Lin, "Licensing strategies in the presence of patent thickets," Journal of Product Innovation Management, vol. 28, no. 5, pp. 698-725, 2011. 


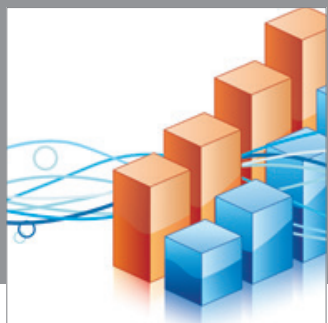

Advances in

Operations Research

mansans

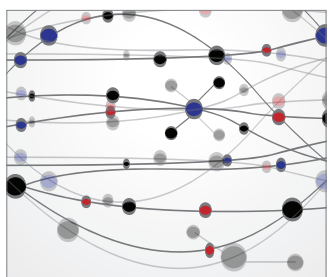

The Scientific World Journal
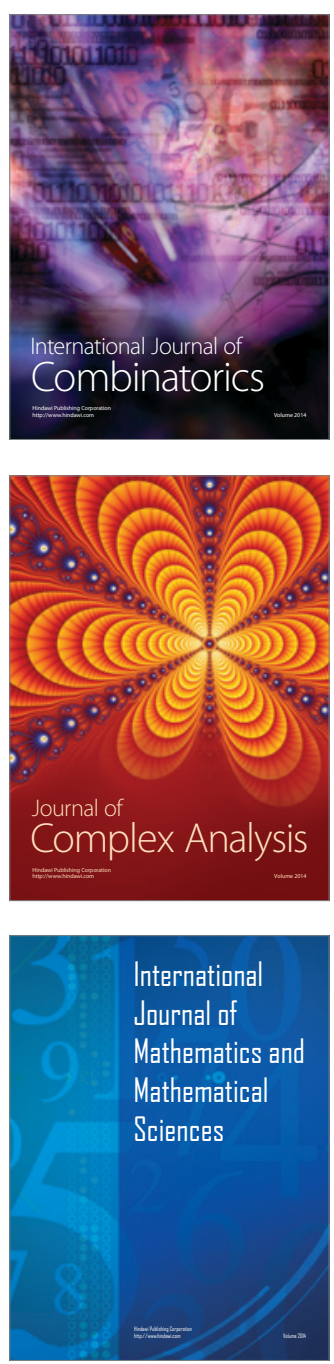
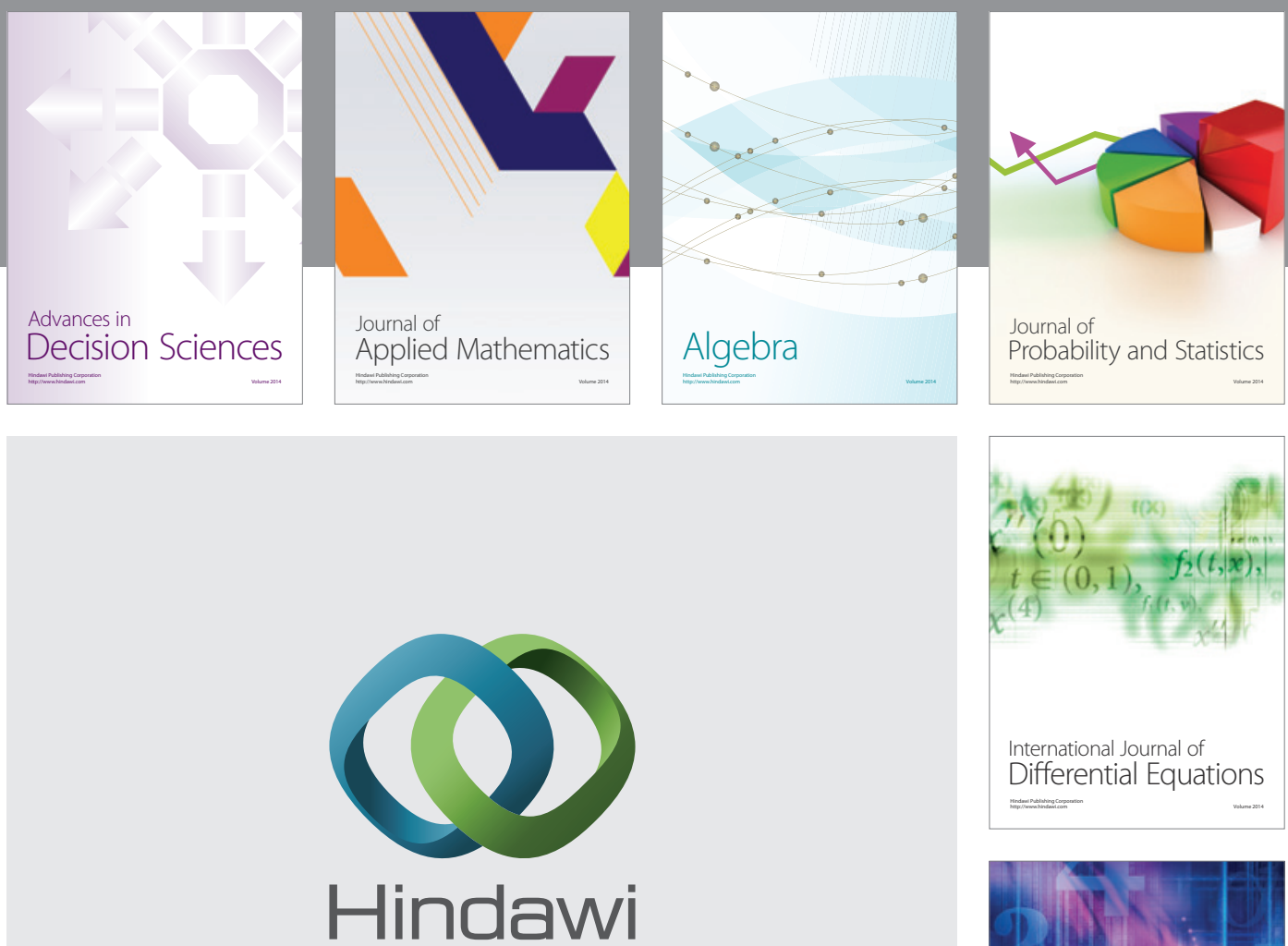

Submit your manuscripts at http://www.hindawi.com
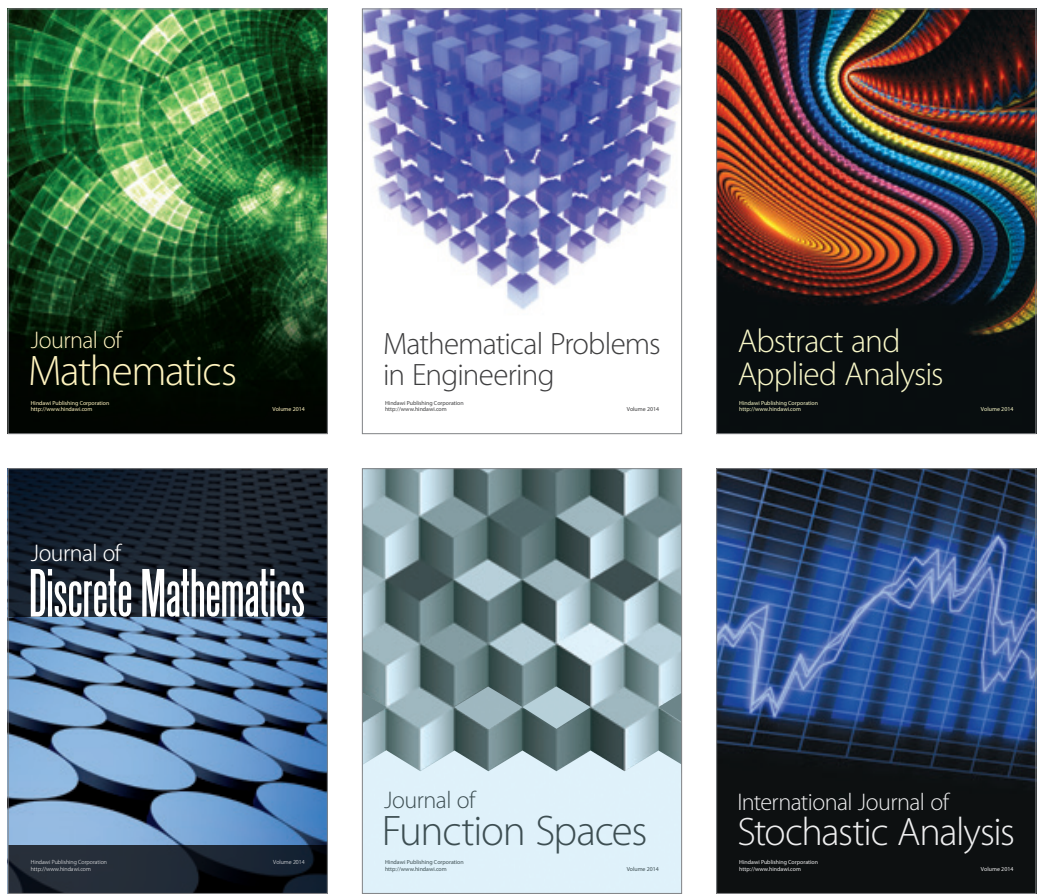

Journal of

Function Spaces

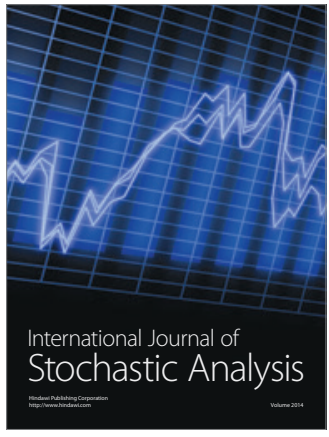

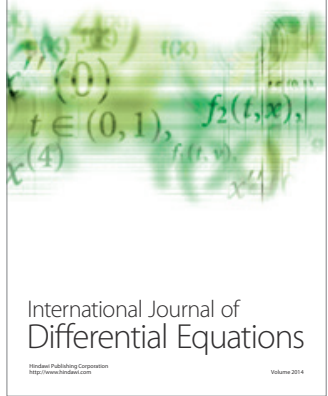
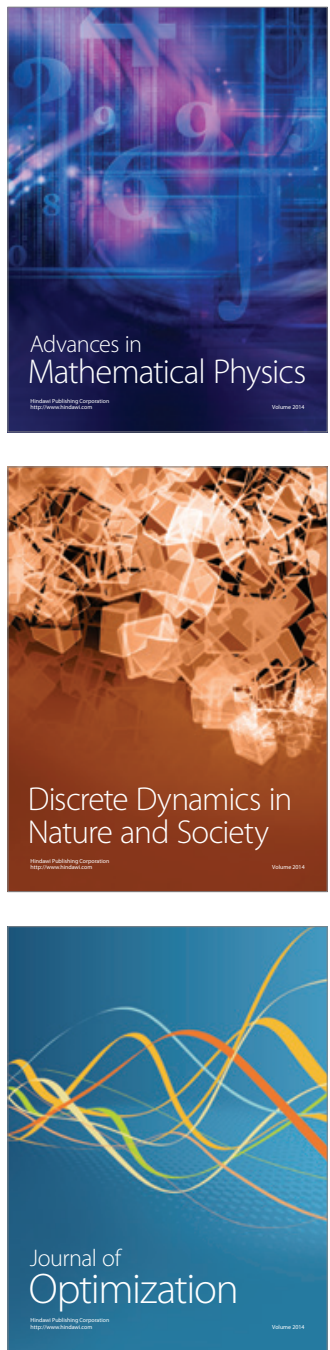